\title{
Artigo
}

\section{MULHER NEGRA IN PROCESS}

\author{
BLACK WOMAN IN PROCESS \\ MUJER NEGRA IN PROCESS
}

Daiana de Moura

Daiana de Moura

Arte-educadora, atriz integrante da Plataforma de Pesquisa Cunhãntã, mestranda do Programa de Pós-Graduação em Educação da UFSCar Sorocaba, bolsista Capes - Demanda Social. 


\section{Resumo}

Por meio da trajetória da pesquisa cênica Cunhãntã, uma atriz discursa em dois eixos centrais: metodologia de pesquisa cênica e sua presença como mulher negra na arte teatral. Esse texto-corpo produz reflexões sobre o fazer teatral visto como território afetivo e como processo de emancipação em trajetórias de vidas de mulheres.

Palavras-chave: Teatro, Processo, Mulher negra.

\section{Abstract}

Through the trajectory of a scenic research, an actress discourses on two central perspectives methodology of scenic research and her presence as a black woman in theatrical art. This "text-body" produces views on theatrical making seen as affective territory and an emancipatory process in the trajectory of women's lives.

Keywords: Theater, Process, Black woman.

\section{Resumen}

Por intermedio de la trayectoria de investigación escénica Cunhãntã, una actriz expone su discurso en dos ejes centrales: como metodología de investigación escénica y su presencia como mujer afrodescendiente en el arte teatral. Este texto-cuerpo plantea reflexiones sobre la labor teatral considerada territorio afectivo y proceso de emancipación en trayectorias de mujeres.

Palabras clave: Teatro, Proceso, Mujer negra.

Este texto-corpo se afirma enquanto urgência. É amolecido pelo desejo da autora de traçar uma escrita que possa dar conta de uma angústia ontológica. Ser pobre e periférica. Ser mulher e negra. Ser atriz e mestranda. Essa reflexão é uma espécie de raio $\mathrm{X}$, ora nítido, ora borrado; difuso. É o registro de uma experiência incrivelmente rica, ditada pelo olhar de um corpo negro atravessado e implicado pelo fazer artístico. Arte que se torna política quando, além de legitimar uma vida, traz questionamentos a ela, outorga um modo de agir, um modus operandi específico no mundo.

Cunhãntã significa, em tupi antigo, mulher dura, mulher guerreira, de poder e de força ${ }^{1}$. E por esse significado se atrelar às suas buscas na arte

1. A língua falada por tupiniquins, potiguaras, tupinambás, temiminós, caetés, tabajaras, tamoios, tupinaés etc., no século XVI era chamada de tupi. Ela designava tanto a língua 
teatral, é que as atrizes Daiana de Moura e Mariana Rossi o escolheram para nomear o que definem como Plataforma de Pesquisa, que transita, desde 2014, pelo teatro, audiovisual, dança e performance, vislumbrando o desejo como uma possível ferramenta artística de libertação, resistência e sobrevivência.

A pesquisa começou quando as atrizes integravam o Coletivo Cê, grupo de teatro sediado no bairro operário da Chave, em Votorantim, com foco no trabalho das mulheres da antiga fábrica de tecidos da cidade. A investigação, que mantinha como pano de fundo a questão das várias jornadas e da subjetividade dessas mulheres, foi guiando as atrizes a perceberem o seu trabalho, suas jornadas e sua subjetividade durante o processo. Dessa forma, o próprio trabalho das atrizes passou a ser também material de investigação para a criação cênica. Assumiram então a noção de redes de conexões, emaranhado de trabalho e desejo. Essa marca passou a ser procedimento: como efetivamente conectar as atrizes às mulheres operárias? O que as separa e o que as une?

Aqui, uma diferenciação entre as atrizes da Plataforma Cunhãntã é necessária para entender o discurso que levam para suas obras: a atriz Mariana Rossi é branca e empreendedora cultural, enquanto a atriz Daiana de Moura é negra e arte-educadora. Observa-se que a primeira mora no centro, enquanto a outra, na periferia, porém ambas estão irmanadas nas lutas que empreendem e procuram trabalhar com as diferenças e não apesar delas.

\section{Encenação e estética}

A peça e as diferentes intervenções da Plataforma Cunhãntã nasceram em ruas e espaços alternativos. Em dezembro de 2016, a Plataforma foi convidada a fazer parte do projeto Coletivações, do Sesc Sorocaba, que subsidia duas apresentações de uma peça do grupo convidado e uma oficina sobre seus procedimentos de criação para interessados em geral. Puderam - com o auxílio de Verônica Veloso, uma orientadora, Douglas Emílio, um preparador corporal de olhar sensível, Márcio Moraes, um produtor, e Vitor Mota,

quanto os índios que a expressavam. No século XVII a chamaram de língua brasílica. Hoje é chamada por estudiosos, como Navarro, de tupi antigo. A palavra atã significa pedra, assim o acompanha diversos termos: Butantã (terra dura, forte), Catanduva (ajuntamento de mata dura, poderosa), Cunhãntã (mulher dura, brava, guerreira) (NAVARRO, 2005). 
um iluminador - identificar as dificuldades de transpor uma peça criada em espaço alternativo para o palco italiano. Nessa empreitada, optaram por verticalizar a investigação corporal, buscando procedimentos condizentes com esse espaço, a peça então passou a ser uma versão específica e ganhou um subtítulo divisor de águas: Cunhãntã: Eu, Ela, Carne, Osso. É a essa etapa da pesquisa cênica que esta escrita se refere. A função de encenador vivida por Bruno Lotelli, que desde o início do processo atua como dramaturgista, agregou sua experiência como diretor de cinema. Encenador, homem e branco, há quatro anos profundamente imerso neste processo, fortaleceu, na estética e no discurso da obra como um todo, o lugar de diversidade, múltiplos olhares sobre o mundo apurando a escuta sensível uns sobre os outros (uma atriz negra, uma atriz branca, um encenador homem, presenças diferentes, imagem que em si contribui para a ideia de empatia, de convivência com as diferenças). Durante esse processo de buscas no palco italiano, a principal referência dramatúrgica foi o romance Parque industrial (GALVÃO, 1994). A partir das imagens do romance, três cores emergiram: preto, branco e vermeIho, as quais atravessam todo o processo criativo e colaboram com a escolha de viver a encenação num encadeamento de fragmentos, coerente com as mulheres da fábula que possuem parcos recursos. Auxiliada pela projeção de textos-enunciados de algumas cenas, a luz, assim como a cenografia, de forma precisa, literal e geométrica incide dramaticidade às cenas e aponta para a precariedade assumida no vazio e a solidão das mulheres retratadas. Os elementos da encenação são dramaturgia e enredamentos estéticos.

\section{Resistência}

A sensibilidade do preparador identificou que seria coerente que a "resistência" presente na história das mulheres brasileiras estivesse norteando o desenvolvimento de seu trabalho, esse foco direcionou os jogos e práticas corporais e foi desvelando nosso modus operandi (des)estruturador de cenas. Parte substancial desse processo é o desejo, arcabouço do processo e de um rigor ético, político e estético, um compromisso com a ação cênica. "O rigor aqui é mais da ordem de uma posição ontológica, do que metodológica, intelectual ou erudita, é um rigor ético/estético/político" (ROLNIK, 1993, p. 6). 
Mas desejos podem ser divergentes, conflitantes, e, para que conflitos não fossem improdutivos, a equipe de trabalho se dispôs de forma muito cuidadosa e empática com o trabalho de todos e de cada um, procurando manter os encontros sempre agradáveis, de forma sensível fortalecendo as bases para que a peça fosse contemplada.

Entendendo tanto ensaio quanto apresentação como laboratórios de experimentos, questionando e reinventando o método, desejando trazer para a cena a presença e a essência de figuras como Patrícia Galvão e sua personagem Corina. Assim, além de investir nos procedimentos escolhidos é importante fazer que estes sirvam eles mesmos como "cena"; ou, que imbricados nesse entendimento, a sustentem em sua busca. Nessa ótica, a cena é a busca dela mesma. É o esforço da atriz em busca de si, em enredamento com a figura que irá desenvolver com aberturas para descobertas que se dão no instante das apresentações-ensaios. A cena é uma superposição de informações, hibridização criada pelos entrelaçamentos de interesses, similaridades e diferenças que aproximam a dinâmica de criação da Plataforma de Pesquisa Cunhãntã da noção de work in process.

Conceitualmente, a expressão work in process carrega a noção de trabalho e de processo. [...] Como trabalho, tanto no termo original quanto na tradução, se acumulam dois momentos: um, de obra acabada, como resultado, produto; e, outro, do percurso, processo, obra em feitura. Como processo implica iteratividade, permeação [...]. Estabelece-se, portanto, uma linguagem que se concretiza enquanto percurso-processo e, enquanto produto, obra gestada nesta trajetória. (COHEN, 2004, p. 21)

Noção que coloca a obra também dentro de um discurso político que revela o território do teatro com métodos e produtos que dizem respeito a servir ou não determinadas lógicas, lugar de disputa de poderes, que tem a ver com o poder de fala, de ser vista e ouvida. Neste espaço, a mulher pode (r)existir, dando vazão aos desejos, aos gritos emergentes e denunciantes, um chão de trabalho e de luta que está sendo constantemente transformado. A cena não possui certezas. É um lugar de abismo. Tanto que os ensaios precisam ser reinventados, as cenas são (des)construídas em jogos corporais, improvisações e propostas abertas das atrizes; depois são escritas e refeitas, sendo alteradas-transmutadas pelo corpo, voltando novamente para o papel, e esse processo 
vai elucidando muitas questões para todos envolvidos. Esse vai e vem de corpo-texto e texto-corpo alcança um textocorporal ou um corpotextual. Tem-se que, nessa conjuntura de fatores, a peça não está a serviço da plateia, está junto com, está em relação. Admite-se que a cena não está pronta, não se define o que ela é, pois atrizes e espectadores trabalham juntos nessa tessitura quando estão presentes no teatro. Por esse motivo, o território afetivo precisa ser discutido e cultivado no dia a dia para sentir-se livre e em busca constante de sororidade entre as atrizes, no sentido mais ético e profundo do termo, e de empatia entre todas as mulheres e homens da equipe, sentido prático de companheirismo de luta e de afetividade. Igualmente fundamental para a construção desse território, Patrícia Galvão, Suely Rolnik, Angela Davis, Renato Cohen, Eduardo Coutinho, foram referências substanciais para o respaldo teórico. $O$ processo aposta nessa territorialidade afetiva, entendendo também que o corpo da muIher é um tabu. Diferente do construído no imaginário sobre a profissão de atriz, essas sujeitas (ou assujeitadas?) de seu tempo não podem negar as construções culturais que se dão no corpo feminino, também para elas o corpo é uma questão. Para lidar com a nudez, por exemplo, a atriz se desvencilha de uma série de impedimentos sociais. As pesquisadoras veem como desafio o rigor ético e político, pois notam em experiências anteriores que muitas vezes teorias se distanciam das práticas, esvaziam-se de muitas formas quando se pensa a presença da mulher no teatro, principalmente da mulher negra. Parte disso se nota em grupos buscando excessivamente cenas perfeitas, atrizes num esforço esquizofrênico de beleza, o silenciamento de temáticas urgentes para negras, gays, mães; a relação financeira de projetos e editais interferindo no cotidiano e nos processos artísticos. Os novos termos cunhados por movimentos feministas mansplaining (explicações masculinas soberbas em assuntos que não Ihes interessam), manterrupting (quando o homem interrompe a mulher deslegitimando, infantilizando sua fala), bropriating (o homem ganha crédito pela ideia da mulher), gaslighting (o homem invalida, invade ideias e sentimentos da mulher convencendo-a de que ela está louca, paranoica) são recorrentes em alguns grupos. Reiteramos, portanto, a importância das diferenças e o valor do processo, principalmente em relação à discussão sem submissões com os homens artistas numa busca de horizontalidade e equidade. $O$ teatro contemporâneo pode contribuir para essa discussão do corpo da mulher e romper com 
tabus; assumimos, por exemplo, que não é um hobbie, um fetiche, uma mostra de talentos e belezas, mas sim um trabalho, que amalgamado ao processo de criação artística, vivencia o exercício de autonomia e de emancipação.

\section{Ferramentas de criação}

Em Cunhãntã, fluindo por meio do desejo rigoroso de transformação, duas mulheres seguem em busca de coerência com ferramentas e procedimentos. Aproximam-se de suas marcas, no sentido em que coloca Rolnik "a marca conserva vivo seu potencial de proliferação, como uma espécie de ovo que pode sempre engendrar outros devires: um ovo de linhas de tempo" (ROLNIK, 1993, p. 3). Uma mesma marca se revisitada pode gerar muitas outras. Assim, desde 2014, um dos dispositivos de trabalho vem sendo o depoimento.

"Depoimento: testemunho, depor-se, colocar-se, soltar-se". A palavra depoimento traz sentidos de buscas artísticas na contemporaneidade. É fato que, neste tipo de pesquisa, é impossível o distanciamento da atriz com o texto-trabalho. Não sem problemas, obviamente. Aproximar-se do trabalho a ponto de necessitar imprimir nele sua voz como tal é político e indica implicação com a pesquisa, processos de reconhecimento de identidades. Fator preponderante para discussão pela possibilidade de trazer à luz da cena teatral vozes que são silenciadas historicamente, podendo constituir um sentido de autonomia, de defesa de ideais e de grupos. Porém, como todo dispositivo, precisa de contraponto crítico. Sem as devidas adequações o depoimento se esvazia enquanto ferramenta, perde o rigor e se torna um "diário" umbilical pouco produtivo. Em três anos de processo, depoimentos diversos surgiam sempre no mesmo formato: uma atriz no microfone contando uma história que, em algum momento, se encadeia com a dramaturgia como um todo. As pesquisadoras foram provocadas a buscar outras formas de depor: sem palavras, com e sem objetos, com vídeos e sequências coreográficas, apropriando-se de histórias alheias, inventando depoimentos de personagens, com música, em silêncio, enfim, inventando possibilidades de tornar o dispositivo interessante, fugindo da repetição regular e controlada. $O$ depoimento se tornou então um impulsionador para as atrizes verticalizarem seu próprio método e entenderem outros 
lugares de fala, explorando possibilidades de manter as mesmas temáticas sob novas óticas. Assim, podem deformar, derreter, desestabilizar cenas, textos, imagens com possibilidades de se aproximarem e distanciarem, enquanto as fronteiras atriz-persona-personagem-figura se tornam aquosas, não lineares e deixam transparecer mais o exercício, o trabalho da atriz em processo do que uma personagem com vozes, movimentos e trejeitos controlados e cristalizados. É um dispositivo revelador do processo.

Enredamento: essas mulheres e suas histórias estavam enredadas pela noção de trabalho em duas camadas: 1) as atrizes; 2) as personagens do livro Parque industrial (GALVÃO, 1994). Mais tarde, esse enredamento foi se diluindo e se espalhando para questões do corpo, da voz, da encenação. Assim, várias possibilidades de agenciamentos foram enriquecendo o processo criativo, criando aberturas de forma que a criação de cenas, imagens, textos, músicas, coreografias pudessem partir de qualquer uma das camadas em questão.

\section{(Re)Escrevendo a história}

Algumas cenas surgiram enredando a atriz Mariana Rossi e Pagu, autora do romance Parque industrial (Ibid.), e a atriz Daiana de Moura e Corina, mulher negra retratada na obra em questão. O ano imaginário de "192017" (mil novecentos e dois mil e dezessete) foi criado e é nessa temporalidade real-fictícia que esses encontros se dão. Na leitura das pesquisadoras, Otávia é uma personagem autobiográfica de Pagu. No romance proletário, ela é uma jovem operária que conhece o movimento comunista por meio das greves na fábrica e se torna uma militante com muitas contradições. Uma Pagu foi então fabulada, misto dessa figura criada por ela mesma e de passagens de sua biografia real - uma sobreposição. No livro, Corina é uma mulher negra do cortiço do Brás e sua vida sofre um declínio vertiginoso depois que engravida de um jovem branco burguês. Após o relacionamento fracassado, Corina, que não frequentou a escola como as outras meninas brancas, perde o emprego que tinha em um ateliê de costura, é posta na rua por sua mãe e pelo seu padrasto alcoólatra, se vê sozinha na rua, levada à uma vida de prostituição e violências e vai para a cadeia, depois que seu filho nasce como um monstro sem pele, provavelmente devido à alguma doença sexualmente transmissível. 
$\mathrm{Na}$ encenação, Corina tem a fome como leitmotiv, "a noite sempre encontra seu estômago esfomeado" (GALVÃO, 1994, p. 143); mesmo na hora do parto deseja um pão (Figura 1).

Figura 1 - Espetáculo encenado

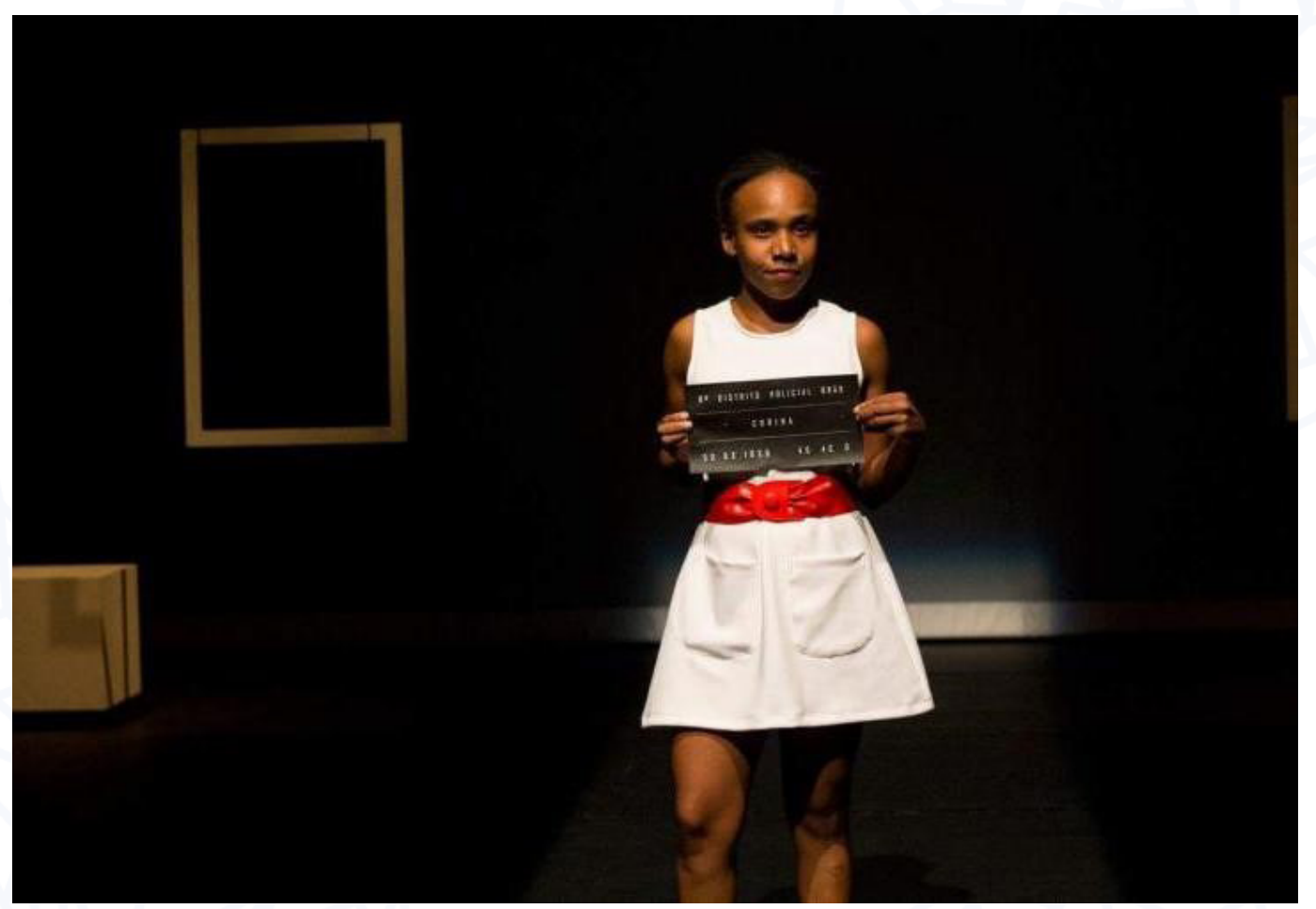

Fonte: Foto de Tatiana Plens (2017)

O fator principal que enreda a atriz Daiana de Moura e a personagem Corina é o contexto social e a busca por esse pão sonhado. Reconhece-se que avanços nas políticas públicas viabilizam que uma mulher negra, atriz, em 2017, tenha acesso a mecanismos (cursos e oficinas de arte, graduação em teatro como bolsista, projetos e editais artísticos e, recentemente, uma bolsa de mestrado) que uma mulher negra apenas sonharia em 1930. Resulta desse enredamento que o lugar em que se dá a dor de Corina não é o fracasso de sua trajetória, mas o fato de ter aprendido a ler na prisão e isso não ter the servido de nada: "Corina saíra da cadeia. Quisera fazer vida nova. Procurara um emprego de criada no Diário Popular. Está pronta a fazer qualquer serviço por qualquer preço. Fora sempre repelida. Entregara-se de novo à prostituição" (GALVÃO, 1994, p. 140). Em Cunhãntã, autora e personagem vão para a mesma prisão, assim saltam aos olhos diferenças e similaridades entre as vidas das duas mulheres, inclusive evidencia que, mesmo Pagu tendo sofrido por ser a primeira presa política do país e por muitos outros fatos políticos, 
a sua história é marcadamente privilegiada pelo fato de ser branca, versus o emaranhado de racismo, machismo, discriminação, preconceito e ódio que a mulher negra e pobre enfrenta. Em determinado momento da peça, tempos depois das duas terem saído da prisão, tencionamos um encontro no qual a personagem cobra da autora uma reescrita justa de sua história. Uma vez que foi alfabetizada na prisão, consciente de sua trajetória, Corina deseja que sua autora desenhe outras possibilidades para as mulheres negras, deseja que histórias tristes e negligenciadas como a sua não sejam mais recorrentes. Pagu responde que não é possível negar a realidade, as mulheres negras estavam sendo omitidas por escritores homens e brancos da época, sua obra não é inventada, mas é o registro de histórias de vidas que pululavam em 1930:

Pagu - O que você queria Corina? Que eu te excluísse do meu livro? Que não tivesse nenhuma mulher negra nele? Ou pior, queria que eu mentisse? Que eu inventasse "o benzinho burguesinho branco engravidou a Corina, preta e pobre, mas ele a amava e a assumiu para sua família, seu filho nasceu saudável e eles vivem felizes num apartamento em Copacabana". Era isso que você queria?

Corina - Queria! Queria que isso fosse possível!

Pagu - A gente não pode omitir a realidade Corina $[\ldots]$

Corina - É esse o seu caderninho? (começando a escrever) Vai começar assim: "É carnaval e todos se divertem. Melhor: todos se divertem o ano inteiro. Corina come todos os dias. Mesa farta [...] seu filho nasceu saudável e foi fazer intercâmbio em Harvard. Corina está feliz porque ela não tem medo que seu filhinho seja morto pela polícia". (CUNHÃNTÃ, 2017)

Esse exercício de fabulação acontece dramaturgicamente quando a realidade não dá conta. O real em excesso pesando sobre a mulher negra é tão duro e absurdo que precisamos esticá-lo, derretê-lo, recriá-lo. Quando a realidade não Ihes representa mais, Pagu e Corina, Mariana e Daiana, fabulam e rompem com o sistema vigente, que lhes impõe padrões estabelecidos, ideais impossíveis nos quais a mulher deve se encaixar. Ao romperem, as atrizes revelam seu não lugar, seu deslocamento, sua falta de encaixe nesses padrões sociais. Provocam e são provocadas pela possibilidade de existir em entropia, em eterno risco, na sensação de estar à beira do abismo. Corina reconhece a impossibilidade de voltar ao passado para reconstruí-lo, mas sem esquecê-lo, passa a contar com suas próprias palavras, outras variáveis para 
sua história. Começa a reescrever sua trajetória na sociedade de forma literal no moleskine de Pagu, que resolve se (re)escrever também e juntas fabulam novos horizontes para a mulher brasileira. Terminam as duas atrizes-personagens movendo seus sonhos de realização profissional no teatro, no instante em que o teatro se dá. Ao final da peça na caixa preta vazia, nota-se dois corpos se auxiliando mutuamente na gestação de um devir para a história da mulher negra. Podemos verificar que conceitos como liberdade, autonomia, emancipação e êxito pessoal/profissional para a mulher negra artista, não estão prontos (e/ou não existem). Fazem-se no percurso, constroem-se em meio a suas trajetórias, dão-se na luta por ser artista, na resistência e na peleja da permanência no teatro. Diante desse escopo que enreda teoria e prática, as atrizes se colocam como mulheres em busca, mulheres em processo. Tornando-se e sendo. Sendo e tornando-se. Estão em exercício.

Quando Corina escreve outra vida possível mostra que mulheres negras e brancas nunca partem do mesmo lugar social. Temos muito que nos unir, mas temos que ter ciência do processo histórico que nos prova e não nos deixa esquecer de tudo o que nos diferencia. $O$ recorte de gênero e raça se faz necessário em toda discussão como esta, que localiza espaços de disputa de poder. Com o modus operandi de Cunhãntã, podemos chegar à conclusão de que a cena, o lugar de disputa política, não está pronta e que mulheres precisam ocupá-la. E aprender a estar. E aprender a aprender enquanto mulheres negras. Colocar o corpo, a voz, a subjetividade e as buscas das mulheres negras na cena teatral contemporânea configura uma experiência estética e política, retira da sombra a imagem de uma mulher que foi ensinada a ser subalterna e submissa, nunca protagonista, intencionalmente ensinada ao silêncio. Nós, mulheres negras, podemos e devemos (r)existir com dignidade e, assim, (re)escrever outra possibilidade. Devires para nossa própria história. Estamos em processo. Mulher negra in process...

\section{Referências bibliográficas}

COHEN, R. Work in progress na cena contemporânea. São Paulo: Perspectiva, 2004.

CUNHÃNTÃ. Eu, ela, carne, osso. Sorocaba, 2017. 
GALVÃO, P. Parque industrial. 3. ed. São Paulo: Mercado Aberto, 1994.

NAVARRO, E. A. Método moderno de tupi antigo: a língua do Brasil nos primeiros séculos. 3. ed. São Paulo: Global, 2005.

ROLNIK, S. Pensamento, corpo, devir. Cadernos de Subjetividade, São Paulo, v. 1, n. 2, p. 1-15, 1993.

Recebido em 08/05/2017

Aprovado em 10/06/2017

Publicado em 05/09/2017 